\title{
Synthesis, Characterization and Performance of a New Type of Alkylene Triphenyl Double Quaternary Phosphonium Salt ${ }^{*}$
}

\author{
Wei Wei, Bin Yuan", Song Lv, Qifeng Liao, Jieyang Huang \\ Faculty of Environmental Science \& Engineering, Guangdong University of Technology, Guangdong, China \\ Email: "gdyb1960@126.com
}

Received October 2013

\begin{abstract}
By Bimolecular Nucleophilic Substitution, four new types of alkylene triphenyl double quaternary phosphonium salt were synthesized respectively by using triphenylphosphine, 1,3-dibromopropane, 1,6-dibromohexane, 1,10-dibromodecane, 1,12-dibromododecane as raw materials and using DMAC as the solvent, under a certain temperature and reaction time. The productivity is $58 \%-83 \%$. The molecular structures of the products were characterized by IR, NMR and elemental analysis. The sterilizing effect of 1,6-hexylidene triphenyl double phosphonium bromide (HTDPB) and 1,12dodecylidene triphenyl double phosphonium bromide (DoTDPB) was evaluated by using extinct dilution method. The experimental result shows that the sterilizing effect of DoTDPB is better than the effect of HTDPB under the same drug concentration and contact time. When the concentration of DoTDPB was $20 \mathrm{mg} / \mathrm{L}$ and the contact time was $0.5 \mathrm{~h}$, the sterilizing rate of DoTDPB used to kill saprophytic bacteria (TGB), sulfate-reducing bacteria (SRB) and iron bacteria (IB) was $95.56 \%, 84 \%$ and $99.58 \%$ respectively.
\end{abstract}

Keywords: Alkylene Triphenyl Phosphonium; Double Quaternary Phosphonium Salt; Bactericide; Synthesis; Performance

\section{Introduction}

One traditional way to prevent microbes from breeding in water is adding bactericide in water. If people use the same kind of bactericide frequently, microbes will get resistance to drugs. That will decreases the sterilizing effect of bactericide, and increases the application amount of bactericide and the cost of water treatment, so to make a new type of high-effeciency bactericide has been a research hotspot among domestic and overseas researchers. Quaernary phosphonium salt and double quaernary phosphonium salt are one type of new, high-effeciency and broad-spectrum bactericide [1-3], which will not produce foam after being used in water and exist in the interface and water body. The sulfonated triphenyl phosphonium has the effect of resisting tumour [4], so it is evaluated highly.

Four new types of alkylene triphenyl double quaternary phosphonium salt were synthesized respectively by Bimolecular Nucleophilic Substitution and using triphenyl phosphine, 1,3-dibromo propane, 1,6-dibro mohexane, 1,10-dibromodecane and 1,12-dibromododecane as raw materials. Their synthetic route is in Figure 1.

\footnotetext{
*Supported by the Guangzhou science and technology plan projects (2010Y1-C781).

${ }^{\#}$ Corresponding author.
}

The molecular structures of products were characterized by using IR, NMR and element analysis. The sterilizing effect of 1,6-hexylidene triphenyl double phosphonium bromide (HTDPB) and 1,12-dodecylidene triphenyl double phosphonium bromide (DoTDPB) was tested by using extinct dilution method.

\section{Experimental Part}

\subsection{Reagents and Instruments}

Reagents: Triphenylphosphine, 1,3-dibromomopropane, 1,6-dibromohexane, 1,10-dibromodecane, 1,12-dibromododecane and $\mathrm{N}, \mathrm{N}$-dimethylacetamide are all analytical reagents. Industrial circulating cooling water samples are from a petrochemical corporation in Guangzhou.

Instruments: PE-2400 CHNS elementalanalyser (PerkinElmer of Shanghai); NICOLET-380 infrared spectrometer (Thermo Electron Corporation); XT41-00B

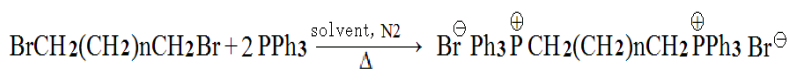

$$
\begin{aligned}
& \mathrm{n}=1,4,8,10
\end{aligned}
$$

Figure 1. The synthetic route of alkylene triphenyl double quaternary phosphonium salt. 
micromelting point apparatus (Keyi photoelectric instrument factory of Beijin); thermometers; Bruker AVANCE III HD 500 NMR spectrometer; 722 ultraviolet and visible spectrophotometer(INESA).

\subsection{The Synthesis of Bactericide}

\subsubsection{The Synthesis of 1,12-Dodecylidene Triphenyl Double Phosphonium Bromide (DoTDPB)}

1,12-dibromododecane (3.28 g, $0.01 \mathrm{~mol})$ and triphenylphosphine (5.78 g, $0.022 \mathrm{~mol}$ ) were added in a threenecked bottle with a thermometer, a condensation tube and the entrance of $\mathrm{N}_{2}$. DMAC (12 ml) was used to dissolve reactants. Under the protection of $\mathrm{N}_{2}$, the reaction proceeded at $150^{\circ} \mathrm{C}$ for $20 \mathrm{~h}$. The product was obtained by using reduced perssure distillation after the reaction. Then, it was dissolved in some distilled water and the aqueous phase was extracted thrice with petroleum ether. We obtained the liquid product (DoTDPB) by using rotary evaporation in the end. The productivity was $82.6 \%$.

\subsubsection{The Synthesis of 1,10-Decylidene Triphenyl Double Phosphonium Bromide (DeTDPB)}

The experimental method was similar to the method in the part 1.2.1. 1,10-dibromodecane (2.44 g, $0.01 \mathrm{~mol})$ and triphenylphosphine (5.78 g, $0.022 \mathrm{~mol}$ ) reacted under the same condition like the part 1.2.1 for $18 \mathrm{~h}$. And then, we obtained the liquid product (DeTDPB). The productivity was $82.8 \%$.

\subsubsection{The Synthesis of 1,6-Hexylidene Triphenyl Double Phosphonium Bromide (HTDPB)}

The experimental method was similar to the method in the part 1.2.1. 1,6-dibromohexane (2.44 g, $0.01 \mathrm{~mol})$ and triphenylphosphine $(5.24 \mathrm{~g}, 0.02 \mathrm{~mol})$ reacted under the same condition like the part 1.2.1. Then, we obtained the solid product (HTDPB). It was recrystallized by using the solvent which was comprised of ethanol $(1 \mathrm{~mol})$ and acetone $(1 \mathrm{~mol})$. The melting point of the product is $324^{\circ} \mathrm{C}-326^{\circ} \mathrm{C}$ and the productivity was $74.5 \%$.

\subsubsection{The Synthesis of 1,3-Propylidene Triphenyl Double Phosphonium Bromide (PTDPB)}

Under the protection of $\mathrm{N}_{2}$, triphenylphosphine (5.78 g, $0.022 \mathrm{~mol}), 1,3$-dibromomopropane(2.02 g, $0.01 \mathrm{~mol})$ and DMAC $(20 \mathrm{~mL})$ were mixed to react at 120 $125^{\circ} \mathrm{C}$ for $10 \mathrm{~h}$. After the rection, the precipitate in the solvent were filtered out and dissolved in the distilled water $(210 \mathrm{ml})$. The insoluble matters in the distilled water were filtered out, and the aqueous phase was evaporated by using rotry evaporation. The residual solids was recrystallized by using the same solvent mentioned at the part 1.2.3 and dried in vacua untill their weight was constant. The melting point of the product is $350^{\circ} \mathrm{C}$ - $352^{\circ} \mathrm{C}$ and the productivity was $57.7 \%$.

\subsection{Bactericidal Experiments}

By using MPN [5] to measure the change of bacterial concentration of water samples, the sterilizing effect of bactericide was tested. The water samples used in the bactericidal experiments was from a petrochemical corporation in Guangzhou. The bacteria used in the bactericidal experiments were saprophytic bacteria (TGB), sulfate-reducing bacteria (SRB) and iron bacteria (IB).

\subsection{The Determination of the Phosphorus Content of Products}

The total phosphorus content of products disposed by using microwave digestion was determined by using ammonium molybdate spectrophotometric method [6]. The phosphorus content of products was calculated by using the formula (1).

$$
p(\%)=\left(G \times 10^{-3} / W\right) \times 100
$$

$G(\mu \mathrm{g})$ - The phosphorus content of tested products; $W(\mathrm{mg})$ - The weight of products.

\subsection{The Determination of Dissociative Bromine}

A certain amount of triphenyl double quaternary phosphonium salt was added in a $250 \mathrm{~mL}$ conical flask and dissolved in distilled water under being heated and stirred. When the temperature of the liquid fell to the room temperature, $1 \mathrm{ml}$ potassium chromate solution (5\%) was added in the liquid. After that, the liquid was titrated with silver nitrate standard solution until brick-red precipitate appeared. The wasting volumes of silver nitrate standard solution were recorded. The percentage content of dissociative bromine was calculated by using formula (2).

$$
\eta=\frac{79.904 \mathrm{CV}}{\mathrm{W}} \times 100 \%
$$

$V(\mathrm{ml})$ - The wasting volume of $\mathrm{AgNO}_{3}$ standard solution during titration;

$C(\mathrm{~mol} / \mathrm{L})$ - The concentration of $\mathrm{AgNO}_{3}$ standard solution;

W (mg) - The weight of samples.

\section{The Results of Experiments and Discussion}

\subsection{The Results of Elemental Analysis}

Figure 2 is phosphorus standard curve. The linear equation is $Y=51.3 A-0.1794, R_{2}=0.9997$. The bromine content of products was tested by using the method in part 1.5. The results of elemental analysis about $\mathrm{C}, \mathrm{H}, \mathrm{P}$, $\mathrm{Br}$ are in Table $\mathbf{1 .}$

According to the datas in Table 1, we can see that the 
theorelical values and test values of elemental content of four products are nearly equal.

\subsection{The Results of IR}

The characteristic absorption peaks of four products were detected by using potassium bromide pressed-disk technique. The result is in Table 2.

From those characteristic peaks, the main functional groups of products were confirmed.

\subsection{The Results of NMR}

The conditions of tests: CD3OD (solvent), $25^{\circ} \mathrm{C}$ (temperature), TMS (internal standard).

The results of $1 \mathrm{HNMR}$ and $13 \mathrm{CNMR}$ about four products are in Table 3 and Table 4.

According to the experimental results of NMR, the inference about the molecular structures of four products is correct.

\subsection{The Results of Sterilization Experiment}

When bactericide concentration was $20 \mathrm{mg} / \mathrm{L}$ and contact time was $1 \mathrm{~h}$, the effect of killing saprophytic bacteria (TGB), sulfate-reducing bacteria (SRB) and iron bacteria (IB) with two types of quaternary phosphonium salt was tested, and the results are in Table 5.

From Table 5, we see that two products have good effect of killing IB, and their sterilizing rate is all more than $99 \%$ under the experimental conditions.

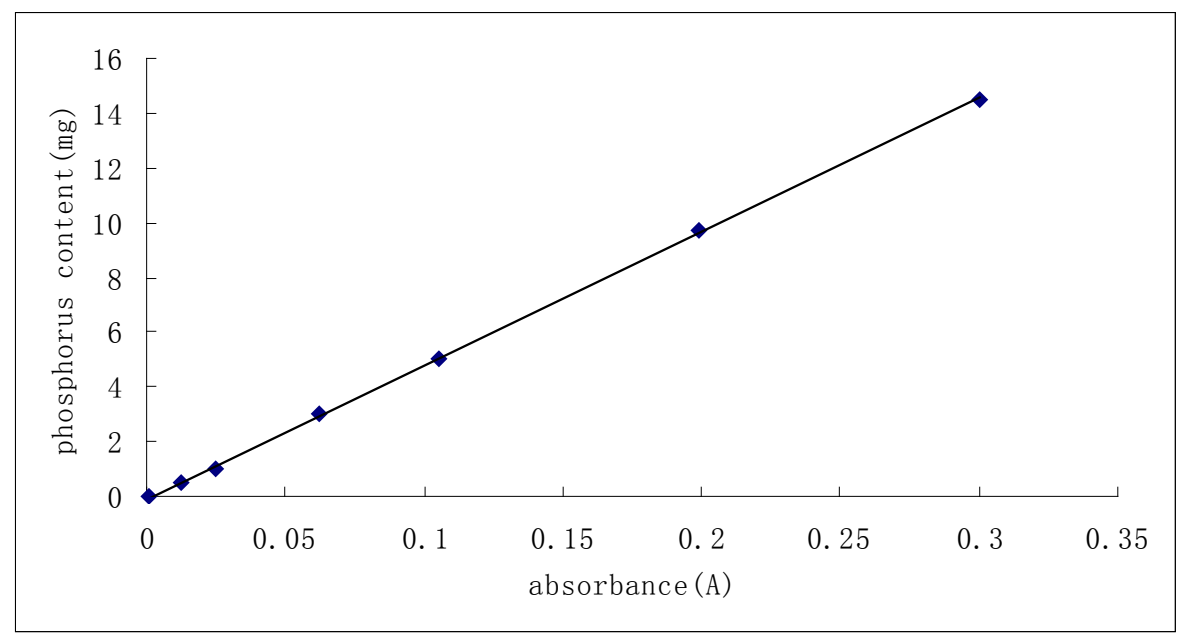

Figure 2. The standard curve of phosphorous.

Table 1. The results of elemental analysis about four types of double quarternary phosphonium salt.

\begin{tabular}{|c|c|c|c|c|c|c|c|c|}
\hline \multirow{2}{*}{ 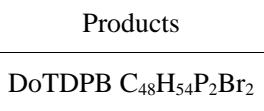 } & \multicolumn{2}{|c|}{ C (\%) } & \multicolumn{2}{|c|}{ H (\%) } & \multicolumn{2}{|c|}{$\mathrm{P}(\%)$} & \multicolumn{2}{|c|}{$\mathrm{Br}(\%)$} \\
\hline & $67.61(a)$ & $67.57(b)$ & 6.38 & 6.34 & 7.26 & 7.15 & 18.74 & 18.49 \\
\hline HTDPB $\mathrm{C}_{42} \mathrm{H}_{42} \mathrm{P}_{2} \mathrm{Br}_{2}$ & 65.64 & 65.61 & 5.51 & 5.55 & 8.06 & 7.99 & 20.80 & 20.85 \\
\hline PTDPB $\mathrm{C}_{39} \mathrm{H}_{36} \mathrm{P}_{2} \mathrm{Br}_{2}$ & 64.48 & 64.39 & 4.99 & 5.04 & 8.53 & 8.50 & 22.00 & 21.41 \\
\hline
\end{tabular}

$a$-Theorelical values; $b$-Test values.

Table 2. The infrared characteristic absorption peaks of products.

\begin{tabular}{ll}
\hline Products & The infrared characteristic absorption peaks/cm ${ }^{-1}$ \\
\hline DoTDPB & $2985 \sim 2875$ (The stretching vibration of $\mathrm{CH}_{2}$ ); 1646, 1488(The vibration of benzene ring); 850 (The stretching vibration of C-P) \\
DeTDPB & $\begin{array}{l}2927 \sim 2855 \text { (The stretching vibration of } \mathrm{CH}_{2} \text { ); 1635, 1585, } 1464 \text { (The vibration of benzene ring); } 995 \text { (The stretching vibration of } \\
\text { C-P) }\end{array}$ \\
HTDPB & $2975 \sim 2845$ (The stretching vibration of $\mathrm{CH}_{2}$ ); 1686, 1483 (The vibration of benzene ring); 750 (The stretching vibration of C-P) \\
PTDPB & $2932 \sim 2865$ (The stretching vibration of $\mathrm{CH}_{2}$ ); 1656, 1463 (The vibration of benzene ring); 795 (The stretching vibration of C-P) \\
\hline
\end{tabular}


Table 3. The results of 1HNMR about four products.

\begin{tabular}{|c|c|}
\hline Products & The chemical shift in ${ }^{1} \mathrm{HNMR} / \delta$ (ppm) \\
\hline DoTDPB & $\begin{array}{l}\delta=7.67 \sim 7.99(30 \mathrm{H}) \text { (The chemical shift of } \mathrm{H} \text { on benzene ring); } \\
\left.\delta=3.63 \sim 3.68(4 \mathrm{H}) \text { (The chemical shift of } \mathrm{H} \text { on } \mathrm{CH}_{2} \text { that is connected with } \mathrm{P}\right) ; \\
\left.\delta=1.73 \sim 1.79(4 \mathrm{H}) \text { (The chemical shift of } \mathrm{H} \text { on } \mathrm{CH}_{2} \text { that is separated by one } \mathrm{C} \text { from } \mathrm{P}\right) ; \\
\left.\delta=1.64 \sim 1.71(4 \mathrm{H}) \text { (The chemical shift of } \mathrm{H} \text { on } \mathrm{CH}_{2} \text { that is separated by two } \mathrm{C} \text { from } \mathrm{P}\right) ; \\
\left.\delta=1.37 \sim 1.38(4 \mathrm{H}) \text { (The chemical shift of } \mathrm{H} \text { on } \mathrm{CH}_{2} \text { that is separated by three } \mathrm{C} \text { from } \mathrm{P}\right) ; \\
\delta=1.27 \sim 1.30(8 \mathrm{H}) \text { (The chemical shift of other } \mathrm{H}) ;\end{array}$ \\
\hline DeTDPB & $\begin{array}{l}\delta=7.77 \sim 7.94(30 \mathrm{H}) \text { (The chemical shift of } \mathrm{H} \text { on benzene ring); } \\
\left.\delta=3.42 \sim 3.48(4 \mathrm{H}) \text { (The chemical shift of } \mathrm{H} \text { on } \mathrm{CH}_{2} \text { that is connected with } \mathrm{P}\right) ; \\
\left.\delta=1.66 \sim 1.71(4 \mathrm{H}) \text { (The chemical shift of } \mathrm{H} \text { on } \mathrm{CH}_{2} \text { that is separated by one } \mathrm{C} \text { from } \mathrm{P}\right) ; \\
\left.\delta=1.54 \sim 1.59(4 \mathrm{H}) \text { (The chemical shift of } \mathrm{H} \text { on } \mathrm{CH}_{2} \text { that is separated by two } \mathrm{C} \text { from } \mathrm{P}\right) ; \\
\delta=1.28 \sim 1.36(8 \mathrm{H}) \text { (The chemical shift of other } \mathrm{H})\end{array}$ \\
\hline HTDPB & $\begin{array}{l}\delta=7.76 \sim 7.93(30 \mathrm{H})(\text { The chemical shift of } \mathrm{H} \text { on benzene ring); } \\
\delta=3.45 \sim 3.49(4 \mathrm{H})\left(\text { The chemical shift of } \mathrm{H} \text { on } \mathrm{CH}_{2} \text { that is connected with } \mathrm{P}\right) ; \\
\delta=1.66(8 \mathrm{H})\left(\text { The chemical shift of } \mathrm{H} \text { on } \mathrm{CH}_{2} \text { that is separated by one } \mathrm{C} \text { from } \mathrm{P}\right) ; \\
\delta=7.78 \sim 7.96(30 \mathrm{H}) \text { (The chemical shift of } \mathrm{H} \text { on benzene ring); }\end{array}$ \\
\hline PTDPB & $\begin{array}{l}\delta=3.54 \sim 3.75(4 \mathrm{H})\left(\text { The chemical shift of } \mathrm{H} \text { on } \mathrm{CH}_{2} \text { that is connected with } \mathrm{P}\right) \\
\delta=2.21 \sim 2.28(2 \mathrm{H})\left(\text { The chemical shift of } \mathrm{H} \text { on } \mathrm{CH}_{2} \text { that is separated by one } \mathrm{C} \text { from } \mathrm{P}\right) ;\end{array}$ \\
\hline
\end{tabular}

Table 4. The results of $13 C N M R$ about four products.

\begin{tabular}{|c|c|}
\hline Products & The chemical shift in ${ }^{13} \mathrm{CNMR} / \delta$ (ppm) \\
\hline DoTDPB & $\begin{array}{l}\delta=129.9 \sim 136.1 \text { (The chemical shift of } C \text { on benzene ring); } \\
\delta=119.4 \sim 129.9 \text { (The chemical shift of } C \text { that is connected with } \mathrm{P} \text { ); } \\
\delta=29.5 \sim 31.3 \text { (The chemical shift of } C \text { that is separated by one } C \text { from P); } \\
\delta=21.6 \sim 23.4 \text { (The chemical shift of other } C \text { ); }\end{array}$ \\
\hline DeTDPB & $\begin{array}{l}\delta=131.5 \sim 140.1 \text { (The chemical shift of } C \text { on benzene ring); } \\
\delta=119.7 \sim 120.4 \text { (The chemical shift of } C \text { that is connected with P); } \\
\delta=29.9 \sim 35.4 \text { (The chemical shift of } C \text { that is separated by one } C \text { from P); } \\
\delta=22.5 \sim 26.9 \text { (The chemical shift of other } C \text { ); }\end{array}$ \\
\hline HTDPB & $\begin{array}{l}\delta=131.5 \sim 136.3 \text { (The chemical shift of } C \text { on benzene ring); } \\
\delta=119.6 \sim 120.3 \text { (The chemical shift of } C \text { that is connected with P); } \\
\delta=30.6 \sim 30.7 \text { (The chemical shift of } C \text { that is separated by one } C \text { from P); } \\
\delta=22.5 \sim 23.3 \text { (The chemical shift of other } C \text { ); }\end{array}$ \\
\hline PTDPB & $\begin{array}{l}\delta=131.5 \sim 136.5 \text { (The chemical shift of } C \text { on benzene ring); } \\
\delta=119.2 \sim 119.9 \text { (The chemical shift of } C \text { that is connected with } \mathrm{P} \text { ); } \\
\delta=33.0 \sim 33.2 \text { (The chemical shift of } C \text { that is separated by one } C \text { from } P \text { ); }\end{array}$ \\
\hline
\end{tabular}

Table 5. The effect of killing TGB, SRB and IB with products.

\begin{tabular}{cccc}
\hline \multirow{2}{*}{ Products } & \multicolumn{3}{c}{ The sterilizing rate (\%) } \\
\cline { 2 - 4 } & TGB & SRB & IB \\
\hline HTDPB & $91.11 \%$ & $62 \%$ & $99.29 \%$ \\
DoTDPB & $95.56 \%$ & $84 \%$ & $99.58 \%$ \\
\hline
\end{tabular}

\section{Conclusion}

1) The molecular structures of four types of double quaternary phosphonium salt sythesised with triphenyl phosphine, 1,3-dibromopropane, 1,6-dibromohexane, 1,10dibromodecane and 1,12-dibromododecane by Bimolecular Nucleophilic Substitution are confirmed by using element analysis, IR and NMR.

2) The results of sterilizing experiments can indicate that the sterilizing effect of 1,12-dodecylidene triphenyl double phosphonium bromide (DoTDPB) is better than 1,6-hexylidene triphenyl double phosphonium bromide
(HTDPB). The best conditions of sterilization are that the concentration of products is $20 \mathrm{mg} / \mathrm{L}$ and the contact time is $1 \mathrm{~h}$. The sterilizing rate of killing TGB, SRB and IB with 1,12-dodecylidene triphenyl double phosphonium bromide (DoTDPB) were $95.56 \%$, 84\% and 99.58\% respectively.

\section{REFERENCES}

[1] A. Kanazawa, T. Lkeda and T. Endo, "Synthesis and Antimicrobial Activity of Dimethyl- and Trimethyl-Substituted Phosphonium Salts with Alkyl Chains of Various Lengths," Antimicrobial Agents and Chemotherapy, Vol. 38, No. 5, 1994, pp. 945-952. http://dx.doi.org/10.1128/AAC.38.5.945

[2] J. Curtze, "Phosphonium Salts and Fungicidal Use," US Patent No. 4,933,328, 1990.

[3] D. Villemin, M. A. Didi and B. Makhoukhi, "Selective Synthesis of Mono or Diphosphonium Salts-Solvent Effect," Letters in Organic Chemistry, Vol. 4, No. 7, 2007, pp. 509-511. http://dx.doi.org/10.2174/157017807782006272 
[4] Z.-W. Lou and X.-M. Shang, "Synthesis and Antitumor Activities of Sulfonated Triphenylphosphoniums," Chinese Journal of Medicinal Chemistry, Vol. 10, No. 3, 2000, pp. 168-171.

[5] SY/T 0532-2012, "Analysis Method of the Bacteria for
Oilfield Injecting Water. Disappearing Dilution Method”.

[6] GB 11893-1989, "Water Quality-Determination of Total Phosphorus-Ammonium Molybdate Spectrophotometric Method”. 